\title{
Workload composition of the organic horticulture
}

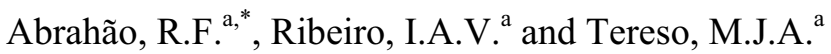 \\ ${ }^{\mathrm{a}}$ Faculty of Agriculture Engineering, Campinas State University, 501 Candido Rondon Ave, 13083-875, \\ Campinas, SP, Brazil
}

\begin{abstract}
This project aimed the characterization of the physical workload of the organic horticulture by determining the frequency of exposure of operators to some activity categories. To do this, an adaptation of the PATH method (Posture, Activities, Tools and Handling) was done to be used in the context of agriculture work. The approach included an evaluation of physical effort demanded to perform the tasks in the work systems from an systematic sampling of work situations from a synchronized monitoring of the heart rate; a characterization of posture repertoire adopted by workers by adapting the OWAS method; an identification of pain body areas using the Corlett diagram; and a subjective evaluation of perceived effort using the RPE Borg scale. The results of the individual assessments were cross correlated and explained from an observation of the work activity. Postural demands were more significant than cardiovascular demands for the studied tasks, and correlated positively with the expressions of bodily discomfort. It is expected that, besides the knowledge obtained of the physical effort demanded by organic horticulture, this project will be useful for the development of new technologies directed to minimize the difficulties of the human work and to raise the work productivity.
\end{abstract}

Keywords: physical workload, organic horticulture, postural analysis, heart rate

\section{Introduction}

There are many researches on organic agriculture regarding technical, economic or ecological issues; few researches, however, try to identify the characteristics of the human workload of the organic agriculture, under an ergonomic perspective [8]. Among organic production, horticulture has undergone a huge growth in Brazil and represents an important economic sector.

Table 1 shows the main work systems and tasks of organic horticulture [9].

Table 1

Work systems and tasks of the organic horticulture

\begin{tabular}{|c|c|c|c|c|c|}
\hline $\begin{array}{c}\text { SOIL } \\
\text { PREPARATION }\end{array}$ & $\begin{array}{c}\text { SEEDING } \\
\text { PRODUCTION }\end{array}$ & PLANTING & $\begin{array}{c}\text { CROP } \\
\text { HANDLING }\end{array}$ & HARVEST & $\begin{array}{l}\text { POST - HAR- } \\
\text { VEST }\end{array}$ \\
\hline bed preparation & hotbed preparation & irrigation & inspection & harvest & cleaning \\
\hline $\begin{array}{l}\text { fertilizer prepara- } \\
\text { tion }\end{array}$ & sowing & seedling & hoeing & pre-cleaning & selection \\
\hline fertilization & & $\begin{array}{l}\text { seedling distribu- } \\
\text { tion }\end{array}$ & fertilization & packing & packing \\
\hline mulching & & root planting & irrigation & transporting & storage/delivery \\
\hline
\end{tabular}

\footnotetext{
*Corresponding author. E-mail: roberto@feagri.unicamp.br $1051-9815 / 12 / \$ 27.50$ C 2012 - IOS Press and the authors. All rights reserved
} 
Being mostly a non repetitive, non monotonous type of work, agricultural work needs a group of methods, both objective and subjective, to characterize its workload. A method that can help the characterization is P.A.T.H. (Posture, Activities, Tools and Handling), an observational work sampling approach developed for the analysis of construction work [1]. The method was developed to measure the frequency of exposure of the workers, as a proportion of observations, to manual materials handling activities and body postures, through an adaptation of the OWAS method of postural analysis. It was originally applied in the analysis of the work done in the building sector.

Heart rate is traditionally used as an indicator of physiological effort, being increasingly used instead of oxygen consumption to estimate the workload of a task [5]. Cardiovascular parameters commonly used include the average heart rate during work - the working heart rate $\left(\mathrm{HR}_{\mathrm{W}}\right)$, the resting heart rate $\left(\mathrm{HR}_{\mathrm{R}}\right)$, the maximum heart rate $\left(\mathrm{HR}_{\max }\right)$, the limit heart rate and the relative heart rate (HRR) [6]. HRR at work is an important indicator of physiological strain and should not exceed $40 \%$ for an eight hour period to avoid fatigue [2]. $\mathrm{HR}_{\mathrm{W}}$ is also used as an strain indicator - [7] proposed the following categories of work intensity: light $\left(\mathrm{HR}_{\mathrm{W}}<90\right)$; moderate $\left(90 \leq \mathrm{HR}_{\mathrm{W}}<110\right)$; heavy $\left(110 \leq \mathrm{HR}_{\mathrm{W}}<130\right)$, very heavy $\left(130 \leq \mathrm{HR}_{\mathrm{W}}<150\right)$ and extremely heavy $\left(\mathrm{HR}_{\mathrm{W}}>150\right)$.

The effects of workload on the individual can also be estimated through the use of psychophysical methods (body discomfort and body pain surveys), like the method proposed by Corllet and Manenica [4] that can be applied to assess the physical effects of the workload. Also, to assess the subjective perceived exertion for each work system or task, it can be applied the RPE (rate of perceived exertion) Borg scale [3].

This project aimed the characterization of the physical workload of the organic horticulture by determining the frequency of exposure of operators to some selected activity categories. Although the concept of workload is difficult and hypothetical - it corresponds to the degree of physical, cognitive and psychological mobilization of the worker [8], the study and description of the workload in organic agriculture can help to minimize the difficulties of the human work and to raise the work productivity.

\section{Methods}

Thirteen workers participated in this research eight from farm A and five from farm B. Each subject was voluntary and received adequate information about the research. They were told that they could withdraw from participation at any time, without penalty of any kind and without providing reasons.

During the workday the heart rate (HR) was measured continuously for each subject, synchronized with the video recording. A Polar RS800CX G3 heart rate monitor was used with a sampling rate of 2 seconds.

P.A.T.H. method was modified to allow the characterization of the work in organic horticulture. The postural protocols were adapted to include the characteristics postures of horticultural labor (Figure 1). The postures were captured from video analysis each five seconds during one hour of continuous work of the several tasks between the work systems.

To assess the perceived exertion for each work system or task, each subject had to indicate their perceived exertion in the work systems or tasks at the end of the working day on a rating scale. It was also used a body part discomfort scale to assess the levels of body discomfort of the workers at the end of the workday.

The heart rate indicators adopted in this work were calculated as follows [2,7]:

$$
\begin{aligned}
& H R_{\max }=220-\text { age } \\
& H R_{L}=0,40 .\left(H R_{\max }-H R_{R}\right)-H R_{R} \\
& H R R=\frac{\left(H R_{W}-H R_{R}\right)}{\left(H R_{\max }-H R_{R}\right)} \cdot 100
\end{aligned}
$$




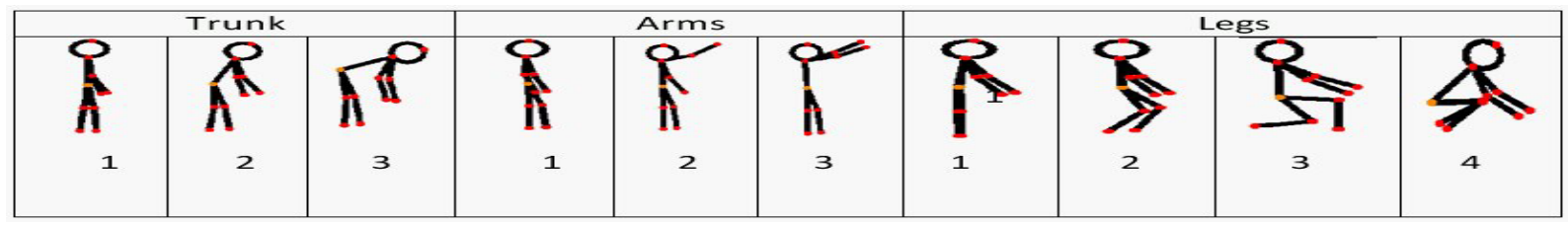

Fig. 1. Posture combinations for trunk, arms and legs.

\section{Results and discussion}

The heart rate results for a workday are summarized on Table 2. Figure 2 shows a typical heart rate recording for a complete workday for worker $1 \mathrm{~A}$.

Table 2 shows that, during the workday, $61,5 \%$ of the workers exhibited $\mathrm{HR}_{\mathrm{W}}$ between 90 and $110 \mathrm{bpm}$, configuring moderate work intensity, while $30,8 \%$ of the workers exhibited relative heart rate (HRR) above $40 \%$, with $\mathrm{HR}_{\mathrm{W}}$ greater than $\mathrm{HR}_{\mathrm{L}}$. The average values of $\operatorname{HR}_{\mathrm{W}}(93,9 \pm 11,2)$ and $\operatorname{HRR}(29,2 \pm 8,8)$ for all the workers during the work day indicate that the overall cardiovascular workload was of moderate intensity.

The postural combinations adopted by the workers in percentage of the working time are expressed on Figure 3 for the work systems and tasks. Four categories were the most frequent, occurring in more than 5\% of the sampling time: (111) - standing, arms down; (211) - moderate trunk flexion $\left(<30^{\circ}\right)$, arms down, extended legs; (212) - moderate trunk flexion $\left(<30^{\circ}\right)$, arms down, flexed legs and (312) - severe trunk flexion $\left(>30^{\circ}\right)$, arms down, flexed legs.

The most severe posture combination - 312 (severe trunk flexion $\left(>30^{\circ}\right)$, arms down, flexed legs) occurred, in average, for the 4 workers, during $79 \%$ of harvesting time, what puts harvest as the most postural demanding work system observed. Post harvest handling and seedling were the least demanding postural activities, where postural combination 111 (standing, arms down) was predominant.

The results of the application of the modified Borg scale for the rate of perceived exertion (RPE) for each work system and task showed that mulching, harvesting and hoeing are perceived by the workers as the activities that are most physically demanding. On the other hand, the post harvest system were perceived as the least intense set of tasks of the organic horticulture.

The results of the of the body discomfort survey showed that all the workers reported discomfort on the back, specially on the lumbar region. The lower limbs were also reported by $69,2 \%$ of the workers, specially the thighs.

\section{Conclusions}

Overall, the results suggest that the adopted approach was efficient to characterize the workload of organic horticulture. The four indicators selected to characterize the workload, which are variables already considered classical in the ergonomic literature - heart rate, postural repertoire, expressions of physical discomfort and rate of perceived exertion seemed to be appropriate to assess the level of effort required by tasks.

The cardiovascular effort was not particularly severe in the tasks analyzed, and rated as moderate for most workers and for most tasks. In the few situations where this indicator was more intense, a more detailed analysis pointed to individual characteristics of the operator as having the greatest influence in this result. It was noticed that certain operational actions relating to manual handling momentarily require a major effort of the cardiovascular system. The same occurs in situations where the worker requires an increase in speed of task execution. Postural demands were more significant than cardiovascular demands for the studied tasks, and correlated positively with the expressions of bodily discomfort.

It is expected that, besides the knowledge obtained of the physical effort demanded by organic horticulture, this project will be useful for the development of new technologies directed to minimize the difficulties of the human work and to raise the work productivity. 
Table 2

Heart rate data for a complete workday

\begin{tabular}{|c|c|c|c|c|c|c|c|c|c|}
\hline Worker & Age & $\begin{array}{c}\text { Weight } \\
\text { (Kg) }\end{array}$ & $\begin{array}{c}\text { Estature } \\
\text { (cm) }\end{array}$ & $\begin{array}{l}\mathrm{HR}_{\mathrm{R}} \\
(\mathrm{bpm})\end{array}$ & $\begin{array}{c}\text { HR }_{\text {MAX }} \\
\text { (bpm) }\end{array}$ & $\begin{array}{c}\mathrm{HR}_{\mathrm{L}} \\
\text { (bpm) }\end{array}$ & $\begin{array}{c}\mathrm{HR}_{\mathrm{W}} \text { (bpm) } \\
( \pm \mathrm{DP})\end{array}$ & $\begin{array}{l}\text { HRR } \\
(\%)\end{array}$ & CATEGORY \\
\hline IA & 44 & 71 & 150 & 56 & 176 & 104.0 & $97,0( \pm 8.9)$ & 34,2 & Moderate $(\mathrm{HRR}<40 \%)$ \\
\hline $2 \mathrm{~A}$ & 25 & 68 & 168 & 52 & 195 & 109.2 & $78,8( \pm 12,0)$ & 18,8 & Light $(\mathrm{HRR}<\mathbf{4 0} \%)$ \\
\hline $3 \mathbf{A}$ & 42 & 67 & 174 & 60 & 178 & 107.2 & $90,6( \pm 11,9)$ & 25,9 & Moderate $(\mathrm{HRR}<\mathbf{4 0 \%})$ \\
\hline 4A & 21 & 72 & 174 & 56 & 199 & 113.2 & $93,9( \pm 16,2)$ & 26,5 & Moderate ( $H R R<40 \%)$ \\
\hline 5A & 28 & 138 & 180 & 64 & 192 & 115,2 & $105,4( \pm 10,3)$ & 32,4 & Moderate $(\mathrm{HRR}<\mathbf{4 0 \%}$ ) \\
\hline $6 \mathrm{~A}$ & 19 & 83 & 155 & 60 & 201 & 116.4 & $104,0( \pm 11,7)$ & 31,2 & Moderate $($ HRR $<\mathbf{4 0} \%)$ \\
\hline $7 \mathrm{~A}$ & 55 & 57 & 148 & 56 & 165 & 99.6 & $72,5( \pm 6,7)$ & 15,2 & Light $($ HRR $<40 \%)$ \\
\hline $8 \mathrm{~A}$ & 41 & 59 & 155 & 60 & 179 & 107.6 & $112,7( \pm 7,1)$ & 44,3 & Heavy (HRR $\geq 40 \%$ ) \\
\hline 9A & 28 & 138 & 180 & 64 & 192 & 115,2 & $88,6( \pm 8,6)$ & 19,2 & Light $(\mathrm{HRR}<\mathbf{4 0} \%)$ \\
\hline 1B & 16 & 70 & 178 & 54 & 204 & 114.0 & $98,5( \pm 9,6)$ & 29,7 & Moderate $(\mathrm{HRR}<40 \%)$ \\
\hline 2B & 67 & 63 & 177 & 64 & 153 & 99.6 & $85,2( \pm 8,5)$ & 23,9 & Light $($ HRR $<40 \%)$ \\
\hline 3B & 47 & 88 & 170 & 60 & 173 & 105.2 & $88,7( \pm 10,5)$ & 25,4 & Light $(\mathrm{HRR}<40 \%)$ \\
\hline 4B & 75 & 65 & 164 & 56 & 145 & 91.6 & $91,0( \pm 7,9)$ & 39,3 & Moderate ( HRR $<40 \%$ ) \\
\hline 5B & 40 & 47 & 146 & 54 & 180 & 104.4 & $107,7( \pm 9,0)$ & 42,6 & Heavy (HRR $\geq 40 \%)$ \\
\hline
\end{tabular}

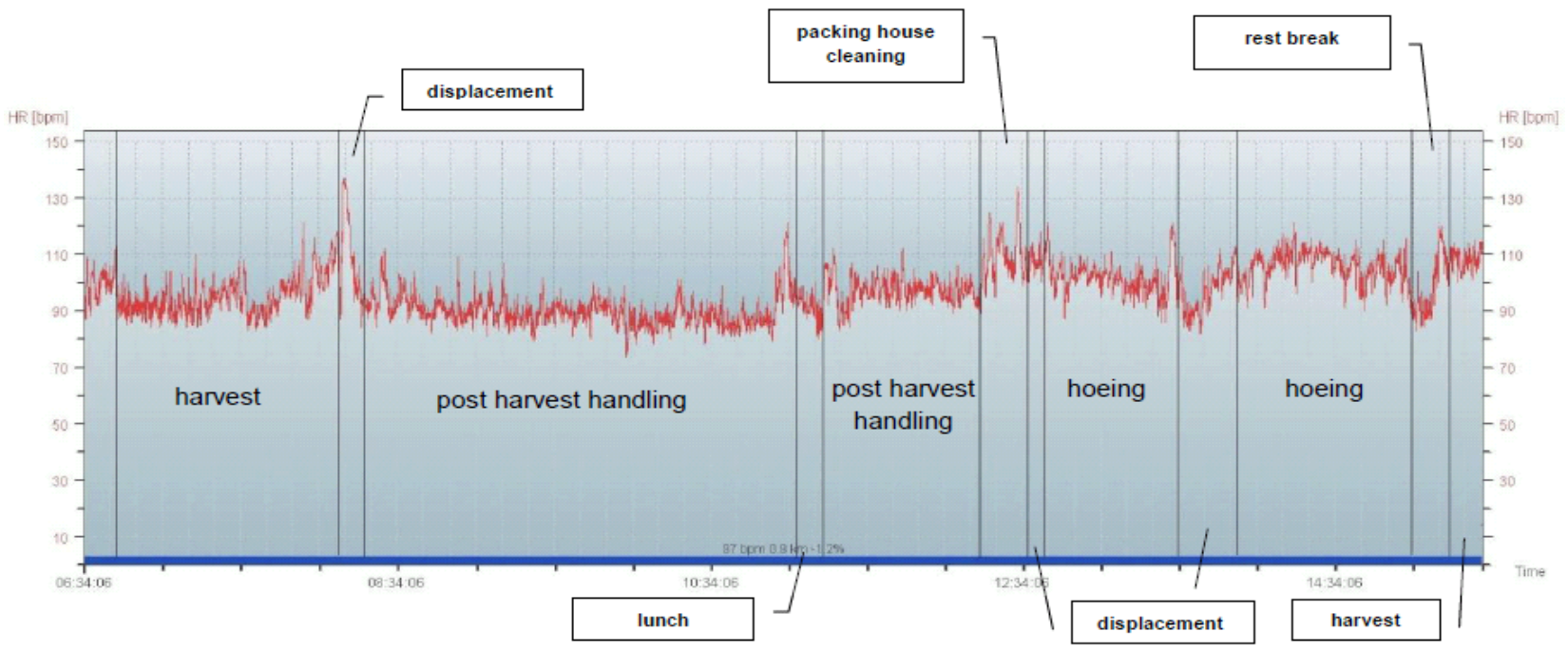

Fig.2. Heart rate data for a complete workday (worker 1A). 


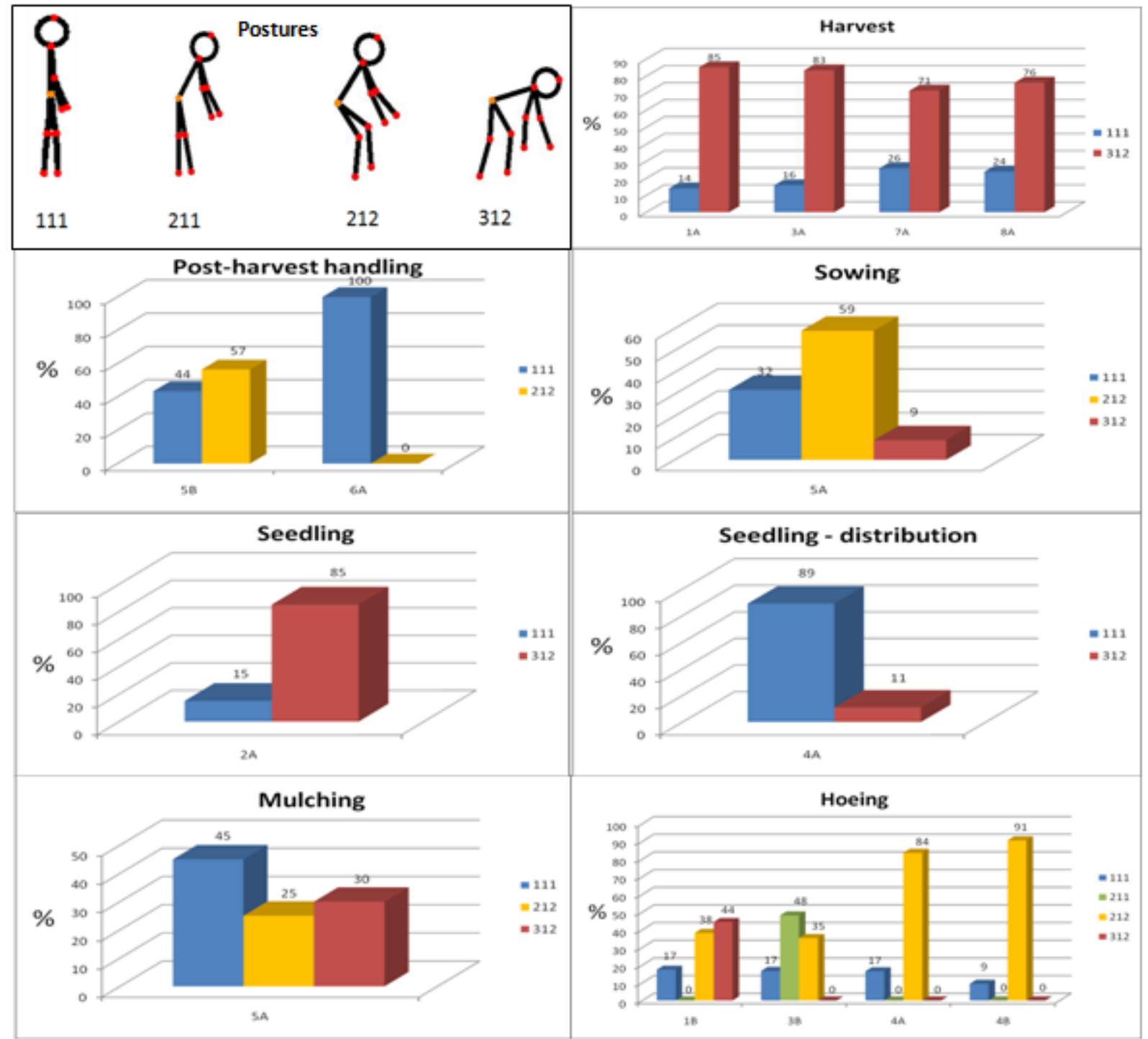

Fig. 3. Posture combinations during work systems and tasks. 


\section{References}

[1] B. Buchholz, V. Paquet, L. Punnett, D. Lee and S. Moir. P.A.T.H.: A work sampling-based approach to ergonomic job analysis for construction and other non-repetitive work. Applied Ergonomics, v 27, n. 23, 1996, pp. 177-187.

[2] E. Apud, L. Bostrand, I.D. Mobs and B. Strehlke. Guidelines on ergonomic study in forestry. Gineva: ILO, (1989).

[3] G. Borg. Escalas de Borg para dor e desconforto percebido. São Paulo: Manole, (2000).

[4] I. Iida Ergonomia: Projeto e produção. 2.ed. São Paulo: Edgar Blücher, (2005).

[5] K. H. E. Kroemer and E. Grandjean. Manual de Ergonomia: adaptando o trabalho ao homem. Porto Alegre: Bookman, (2005).

[6] M.P. Kirk and M.J.M Sullman. Heart rate strain in cable hauler choker setters in New Zeland loggin operations. Applied Ergonomics, 32 (4), (2001) pp. 389-398.
[7] P.Astrand, K. Rodahl and B. Sigmund. Tratado de fisiologia do trabalho: bases fisiológicas do exercício. $4^{\mathrm{a}}$ ed.São Paulo: Artmed, 2006.

[8] P. Falzon and C. Sauvagnac. Carga de trabalho e estresse. In: Ergonomia. Falzon, P. (Editor). São Paulo: Edgar Blucher, (2007), pp.141-154.

[9] R.F. Abrahão, M.J.A. Tereso, S.F.B. Gemma, L.I. Snelwar, F. Mascia. Work and innovation in organic agriculture. In Snelwar, L., Mascia, F. and Montedo, U. (Eds), Proceedings of the 9th International Symposium on Human Factors in Organizational Design and Management. Guarujá: POLI/USP, 2008, pp. 67-71.

[10]S.F.B. Gemma, M.J.A. Tereso, R.F. Abrahão. Complexity and work at organic agriculture. In Snelwar, L., Mascia, F. and Montedo, U. (Eds), Proceedings of the 9th International Symposium on Human Factors in Organizational Design and Management. Guarujá: POLI/USP, 2008, pp. 67-71. 